\title{
BMJ Open A cross-sectional comparison study on the iodine nutritional status between rural and urban residents in Zhejiang Province, China
}

\author{
Yan Zou, Xiaoming Lou, Gangqiang Ding, Zhe Mo, Wenming Zhu, Guangming Mao
}

To cite: Zou Y, Lou X, Ding $G$, et al. A crosssectional comparison study on the iodine nutritional status between rural and urban residents in Zhejiang Province, China. BMJ Open 2014;4:e005484.

doi:10.1136/bmjopen-2014005484

- Prepublication history for this paper is available online. To view these files please visit the journal online (http://dx.doi.org/10.1136/ bmjopen-2014-005484).

Received 16 April 2014 Revised 27 May 2014 Accepted 6 June 2014

CrossMark

Zhejiang Provincial Center for Disease Control and Prevention, Hangzhou, China

Correspondence to Dr Gangqiang Ding; zouyan0573@gmail.com

\section{ABSTRACT}

Objectives: To evaluate the difference of iodine nutritional status between rural and urban residents under the universal salt iodisation policy.

Setting: A multistage cluster sampling technique was employed in the present cross-sectional study. In total, 3300 rural and 3300 urban households were selected where the investigation was conducted.

Participants: A total of 8553 rural and 8909 urban residents participated in this provincial survey.

Primary and secondary outcome measures: Spot urine samples were collected and the iodine concentration in urine was determined by the modified acid-digestion method.

Results: The median urinary iodine concentration of rural residents was $170.1 \mu \mathrm{g} / \mathrm{L}$, which was higher than that of urban residents with $153.5 \mu \mathrm{g} / \mathrm{L}$. For schoolaged children, middle-aged people and older people, the median urinary iodine concentration of rural residents was $191.2,160.2$ and $154.0 \mu \mathrm{g} / \mathrm{L}$, respectively, which was higher than that of urban residents with 166.2, 153.8 and $129.5 \mu \mathrm{g} / \mathrm{L}$, respectively. Risk factors for urinary concentration of rural residents were age $(\mathrm{OR}=0.99)$, terrain $(\mathrm{OR}=0.83)$, usual intake of pickled products $(\mathrm{OR}=1.45)$ and non-iodised salt intake $(\mathrm{OR}=0.39)$, while those for urban residents were age $(O R=0.99)$, terrain $(O R=0.83)$, usual intake of aquatic products $(O R=1.24)$ and non-iodised salt intake $(\mathrm{OR}=0.27)$ compared with iodised table salt intake.

Conclusions: The median urinary iodine concentration of rural residents was higher than that of urban residents although they were both falls in optimal iodine status as recommended by WHO/UNICEF/International Council for the Control of lodine Deficiency Disorders. lodised salt intake is the major factor which influences the iodine nutritional status mostly for rural and urban residents. The ongoing monitoring of population iodine status remains crucially important.

\section{INTRODUCTION}

Iodine is a trace element required by the thyroid gland to produce thyroxine and triiodothyronine, thyroid hormones necessary for multiple processes related to normal

\section{Strengths and limitations of this study}

- Iodine deficiencies were prevalent in China until the introduction of universal salt iodization (USI) in 1995. Economic development had remarkable influence on iodine intake for both rural residents and urban residents, but the difference between rural residents and urban residents under the USI policy has not been evaluated. Iodine nutritional status of rural residents and urban residents stratified by age has not been evaluated. This paper aims to explore the difference of iodine nutritional status between rural residents and urban residents 16 years after the introduction of salt iodization.

- This analysis has several limitations. Urinary iodine concentrations are highly variable and represent recent intake rather than usual intake. Due to this variation, a sample of 100 spot urine tests is needed to produce estimates of urinary iodine with a precision range of $\pm 10 \%$, and a sample of 500 is needed for a precision range of $\pm 5 \%$. Limited by the sample size, the difference of UIC between rural residents and urban residents were not found in some age group and further studies should be carried out to explore the difference, The ongoing monitoring of population iodine status remains crucially important.

growth and development. Globally, 29.8\% of school-aged children (241 million) are estimated to have insufficient iodine intake. ${ }^{1}$ Iodine deficiency was prevalent in China until the introduction of universal salt iodisation (USI) in 1995. In the early 1980s, surveys identified 831000 individuals with iodine deficiency disorders (IDD) manifesting as goitre, and an additional 134 individuals with typical cretinism in Zhejiang Province. Iodised salt has been supplied in Zhejiang Province since 1995, and the median urinary iodine concentration (UIC) of children aged 8-10 years in Zhejiang Province has been adequate or sufficient 
from 1995 to 2011. USI proved very effective; a provincial survey in 2000 found the virtual elimination of IDD. $^{2}$

More than $90 \%$ of dietary iodine eventually appears in the urine; UIC is an excellent biomarker of recent iodine intake. ${ }^{3}$ It is recommended to assess the iodine status of a population. ${ }^{4}$ It is a reliable measure of exposure and a low-median value suggests that a population is at higher risk of developing thyroid disorders. Economic development had remarkable influence on iodine intake for rural and urban residents, but the difference between rural and urban residents under the USI policy has not been evaluated. Therefore, this paper aims to compare UIC of rural and urban residents in Zhejiang Province 16 years after the introduction of salt iodisation in order to explore the influence of factors of iodine nutritional status. The information obtained could provide the basis for further government policymaking.

\section{PARTICIPANTS AND METHODS \\ Participants}

There are 11 cities under the direct jurisdiction of the Zhejiang provincial government, including Hangzhou, Ningbo, Wenzhou, Jiaxing, Huzhou, Shaoxing, Jinhua, Quzhou, Zhoushan, Taizhou and Lishui, under which there are 32 districts, 22 county-level cities and 36 counties. A multistage cluster sampling technique was employed in the present cross-sectional study.

First, a rural area sampling unit (county-level cities) and an urban area sampling unit (counties), respectively, were selected from each city. Then three investigation sites were selected from each sampling unit according to their location in the county-level cities or counties and one community was selected randomly from the sampled investigation site. So totally, 33 rural and 33 urban communities were selected where the investigation was conducted. In every sampled community, 300 households were selected by the random sampling method according to the household registration information. Then every member of the sampled household was interviewed and their urine sample was collected.

\section{Methods}

A questionnaire was designed to obtain general personal information, which included gender, age, residence, information of diet habits, etc. The questionnaire was administrated face to face by trained staff through a door-to-door interview.

\section{Measures}

Spot urine samples were collected and delivered to the local Center for Disease Control and Prevention laboratory for measuring UIC, which was determined by the modified acid-digestion method (method for determination of iodine in urine by As3+-Ce4+ catalytic spectrophotometry, WS/T 107-2006, Ministry of Health People's Republic of China).

\section{Statistical analysis}

As continuous variables were not normally distributed, they were described as the median, 25th and 75th centiles. The differences between rural and urban residents were evaluated by a non-parametric test (Mann-Whitney test). In order to explore the risk factors of UIC, we divided UIC into two concentration groups (group 1: less than $300 \mu \mathrm{g}$ / $\mathrm{L}$; group 2: equal to or more than $300 \mu \mathrm{g} / \mathrm{L}$ ). The following variables were selected as covariates in the models of UIC: age group $(0,1-4,5-9,10-14,15-19,20-24,25-29$, 30-34, 35-39, 40-44, 45-49, 50-54, 55-59, 60-64, 65-69, 70-74, 75-79, 80-84, 85-), gender (male/female), terrain (coastal areas, plain areas or mountain areas), pickled products intake (few or usual), aquatic products intake (few or usual), table salt type (iodised salt or non-iodised salt), salt appetite, dietary patterns and education. Multiple logistic regression was used to explore the influence factors of UIC. Data processing and statistical analyses were performed using SAS V.9.2 software. All tests were two sided and the level of significance was set at $\mathrm{p}<0.05$.

\section{RESULTS}

UIC of people living in rural and urban areas stratified by age

A total of 8553 rural and 8909 urban residents participated in the present survey; the median (25th and 75th centile) of UIC in rural and urban residents was found to be 170.1 (103.9 and 259.8) $\mu \mathrm{g} / \mathrm{L}$ and 153.5 (92.0 and 237.5) $\mu \mathrm{g} / \mathrm{L}$, respectively. UIC of rural and urban residents was presented by age in table 1 .

UIC of rural residents was higher than that of urban residents $(\mathrm{Z}=-10.570, \mathrm{p}=0.000)$. When stratified by age, for 10-, 45-, 60-, 65-, 70-, 75- and 80-year-old people, there were significant differences between rural and urban residents with the same direction (table 2).

\section{UIC of people living in rural and urban areas stratified by} age group (preschool-aged children, school-aged children, adolescents, young people, middle-aged people and older people groups)

In table 2, we combined age groups to preschool-aged children (3-6 years), school-aged children (7-12 years), adolescents (13-18 years), young people (19-39 years), middle-aged people (40-59 years) and older people (60 years and above). Children aged 0-2 years were not included. The median (25th and 75th centile) of UIC in rural and urban residents was found to be 170.1 (103.9 and 259.8) $\mu \mathrm{g} / \mathrm{L}$ and $153.5(92.0$ and 237.4) $\mu \mathrm{g} / \mathrm{L}$, respectively. UIC of rural and urban residents is presented by age groups in table 2 .

UIC of rural residents was higher than that of urban residents $(\mathrm{Z}=-7.365, \mathrm{p}=0.000)$. When stratified by age group, for school-aged children, middle-aged people and older people, there were significant differences between rural and urban residents with the same direction. However, there were no significant differences between rural and urban residents for preschool-aged children, adolescents and young people (table 2). 
Table 1 Urinary iodine concentration (median, 25\% and 75\%) of people living in rural and urban areas stratified by age, Zhejiang Province, China

\begin{tabular}{|c|c|c|c|c|c|c|}
\hline & \multicolumn{2}{|c|}{ Rural areas } & \multicolumn{2}{|c|}{ Urban areas } & \multirow[b]{2}{*}{$\mathbf{Z}$} & \multirow[b]{2}{*}{ p Value } \\
\hline & $\overline{\mathbf{N}}$ & Median (25\%, 75\%; $\mu \mathrm{g} / \mathrm{L})$ & $\overline{\mathbf{N}}$ & Median (25\%, 75\%; $\mu \mathrm{g} / \mathrm{L})$ & & \\
\hline $0-$ & 55 & $188.4(106.5,326.6)$ & 32 & $141.6(102.3,208.6)$ & -1.937 & 0.053 \\
\hline $1-$ & 209 & $186.0(117.5,264.3)$ & 140 & $176.5(91.2,265.8)$ & -0.653 & 0.514 \\
\hline $5-$ & 335 & $176.7(116.0,274.6)$ & 343 & $171.0(112.2,258.5)$ & -0.642 & 0.521 \\
\hline $10-$ & 369 & $198.7(123.8,288.5)$ & 350 & $173.3(108.1,258.4)$ & -2.646 & 0.008 \\
\hline $15-$ & 208 & $190.5(108.5,275.0)$ & 244 & $181.0(102.4,264.2)$ & -0.907 & 0.364 \\
\hline $20-$ & 304 & $163.6(104.4,252.8)$ & 287 & $191.2(111.0,288.1)$ & -0.166 & 0.096 \\
\hline $25-$ & 416 & $167.6(98.1,258.8)$ & 508 & $166.2(99.0,257.7)$ & -0.103 & 0.918 \\
\hline $30-$ & 500 & $173.3(101.8,261.8)$ & 483 & $173.9(108.2,264.5)$ & -0.460 & 0.645 \\
\hline $35-$ & 594 & $178.0(110.2,269.9)$ & 666 & $172.6(105.3,253.6)$ & -1.778 & 0.075 \\
\hline $40-$ & 813 & $170.1(105.0,254.7)$ & 832 & $168.3(104.8,246.5)$ & -0.447 & 0.655 \\
\hline $45-$ & 872 & $169.0(106.5,259.4)$ & 828 & $150.8(90.5,236.5)$ & -3.647 & 0.000 \\
\hline $50-$ & 936 & $152.0(96.0,241.9)$ & 962 & $148.1(85.6,231.8)$ & -1.897 & 0.058 \\
\hline $55-$ & 1049 & $151.3(97.8,240.0)$ & 1078 & $148.7(87.3,238.0)$ & -1.310 & 0.190 \\
\hline $60-$ & 796 & $155.0(95.8,251.1)$ & 869 & $137.0(81.5,218.0)$ & -4.071 & 0.000 \\
\hline $65-$ & 451 & $154.2(91.5,236.9)$ & 478 & $125.2(72.8,204.8)$ & -3.932 & 0.000 \\
\hline $70-$ & 305 & $151.2(91.5,236.9)$ & 340 & $121.7(73.9,219.2)$ & -3.842 & 0.000 \\
\hline $75-$ & 210 & $155.8(92.1,233.3)$ & 297 & $127.5(76.4,200.2)$ & -2.990 & 0.003 \\
\hline $80-$ & 101 & $156.6(103.3,228.4)$ & 125 & $137.0(73.8,219.2)$ & -1.979 & 0.048 \\
\hline $85-$ & 30 & $133.9(76.3,194.4)$ & 47 & $118.0(70.1,166.6)$ & -0.752 & 0.452 \\
\hline Total & 8553 & $170.1(103.9,259.8)$ & 8909 & $153.5(92.0,237.5)$ & -10.570 & 0.000 \\
\hline
\end{tabular}

\section{Multiple logistic regression analysis}

In the multiple logistic regression analysis, UIC was divided into two levels based on the current WHO classification system. In order to explore the risk factors of UIC, we divided UIC into two concentration groups (group1: less than $300 \mu \mathrm{g} / \mathrm{L}$; and group 2: equal to or more than $300 \mu \mathrm{g} / \mathrm{L})$. The regression models for rural and urban areas were both significant $\left(\chi^{2}=251.267\right.$, $\mathrm{p}=0.000$; and $\chi^{2}=316.136, \mathrm{p}=0.000$, respectively). Multiple logistic regression showed that the potential risk factors for urinary concentration of rural residents were age ( $\mathrm{OR}=0.99,95 \%$ CI 0.99 to 0.99$)$, terrain $(\mathrm{OR}=0.83,95 \%$ CI 0.76 to 0.91$)$, usual intake of pickled products ( $\mathrm{OR}=1.45,95 \%$ CI 1.25 to 1.67$)$, non-iodised salt intake $(\mathrm{OR}=0.39,95 \%$ CI 0.31 to 0.49$)$ compared with iodised table salt intake, and the potential risk factors for urinary concentration of urban residents were age $(\mathrm{OR}=0.9,95 \%$ CI 0.98 to 0.99$)$, terrain $(\mathrm{OR}=0.83,95 \%$
CI 0.75 to 0.93$)$, usual intake of aquatic products $(\mathrm{OR}=1.24,95 \%$ CI 1.04 to 1.47$)$, non-iodised salt intake $(\mathrm{OR}=0.27,95 \%$ CI 0.19 to 0.39$)$ versus iodised table salt intake (table 3).

\section{DISCUSSION}

Globally, in 2011, 32 countries and 1.88 billion people remained iodine deficient, including 241 million schoolchildren, who had insufficient dietary iodine intake. Salt iodisation has been recognised as the most effective and cost-efficient strategy to prevent IDD because salt is consumed daily by everybody and by all age groups. ${ }^{6}$ USI was conducted in the Zhejiang Province from 1995. Since October 2000, the iodisation level was set at $35 \mathrm{mg} / \mathrm{kg}$. Presently, surveillance of iodine nutritional status is mainly aimed at school-aged children ${ }^{4}$ because they are a convenient population, easy to reach through

Table 2 Urinary iodine concentration (median, $25 \%$ and $75 \%$ ) of people living in rural and urban areas stratified by age group, Zhejiang Province, China

\begin{tabular}{|c|c|c|c|c|c|c|}
\hline & \multicolumn{2}{|c|}{ Rural areas } & \multicolumn{2}{|c|}{ Urban areas } & \multirow[b]{2}{*}{$\mathbf{Z}$} & \multirow[b]{2}{*}{ p Value } \\
\hline & $\mathbf{N}$ & $\begin{array}{l}\text { Median } \\
(25 \%, 75 \% ; \mu \mathrm{g} / \mathrm{L})\end{array}$ & $\mathbf{N}$ & $\begin{array}{l}\text { Median } \\
(25 \%, 75 \% ; \mu \mathrm{g} / \mathrm{L})\end{array}$ & & \\
\hline Preschool-aged children (3-6) & 238 & $180.9(117.9,275.0)$ & 186 & $181.6(118.2,251.7)$ & -0.776 & 0.438 \\
\hline School-aged children (7-12) & 464 & $191.2(116.7,284.5)$ & 423 & $166.2(107.6,250.8)$ & -2.355 & 0.019 \\
\hline Adolescents (13-18) & 288 & $192.5(117.1,287.6)$ & 371 & $186.0(106.0,276.0)$ & -1.068 & 0.286 \\
\hline Young people (19-39) & 1839 & $171.0(105.0,262.0)$ & 1978 & $174.2(105.2,261.0)$ & -0.435 & 0.664 \\
\hline Middle-aged people (40-59) & 3670 & $160.2(100.2,248.0)$ & 3700 & $153.8(91.6,239.0)$ & -3.587 & 0.000 \\
\hline Older people (60 years and above) & 1893 & $154.0(92.4,245.5)$ & 2156 & $129.5(77.2,206.1)$ & -7.772 & 0.000 \\
\hline Total & 8392 & $170.1(103.9,259.8)$ & 8814 & $153.5(92.0,237.4)$ & -7.365 & 0.000 \\
\hline
\end{tabular}


Table 3 Risk factors of urinary iodine concentration of people living in rural and urban areas, Zhejiang Province, China

\begin{tabular}{|c|c|c|c|c|c|c|c|c|c|c|c|}
\hline Rural areas* & OR & $95 \%$ & & Wald & p Value & Urban areas* & OR & $95 \%$ & & Wald & p Value \\
\hline Age group & 0.99 & 0.99 & 0.99 & 6.04 & 0.014 & Age group & 0.99 & 0.98 & 0.99 & 64.24 & 0.000 \\
\hline Terrain & 0.83 & 0.76 & 0.91 & 17.73 & 0.000 & Terrain & 0.83 & 0.75 & 0.93 & 11.29 & 0.001 \\
\hline Pickled products intake & 1.45 & 1.25 & 1.67 & 25.26 & 0.000 & Pickled products intake & & & & & \\
\hline Aquatic products intake & & & & & & Aquatic products intake & 1.24 & 1.04 & 1.47 & 6.01 & 0.014 \\
\hline Salt type & 0.39 & 0.31 & 0.49 & 67.64 & 0.000 & Salt type & 0.27 & 0.19 & 0.39 & 53.15 & 0.000 \\
\hline
\end{tabular}

school-based surveys and usually representative of the general population. In this study, with the multistage cluster sampling method, all members of the sampled households were investigated covering all age groups. We have known that participants who were the main labour migrants in the rural areas may influence the constituent ratio of age and this situation often exists in the survey. So we compared UIC between rural and urban residents stratified by age group in order to control for the influence of age.

Iodine intake should be modest and appropriate. UIC, with the appropriate sampling method, is currently the most practical biochemical maker for iodine. Our result indicated that the median UIC of rural and urban residents was 170.1 and $153.5 \mu \mathrm{g} / \mathrm{L}$, respectively. According to the $\mathrm{WHO} / \mathrm{UNICEF} /$ International Council for the Control of IDD (ICCIDD), ${ }^{7}$ the recommended dietary allowance of iodine for an adult man is $150 \mu \mathrm{g} /$ day, and the upper daily tolerable intake level of iodine is $1000 \mu \mathrm{g} /$ day according to the Chinese Nutrition Society ${ }^{8}$; according to the report of the Ministry of Health of China, ${ }^{9}$ salt contributed $63.5 \%$ of food iodine and $24.6 \%$ of salt iodine was lost in cooking. Based on these criteria and the result of this study, the current dietary iodine intake of rural and urban residents was 355.3 and $320.6 \mu \mathrm{g} /$ day, respectively, suggesting that the diet iodine intake in the Zhejiang Province is sufficient and safe.

School-aged children are most commonly used as a sentinel population subgroup; ${ }^{4}$ therefore, the WHO/ UNICEF/ICCIDD use urinary concentration from school-aged children to classify a population's iodine status. Based on the previous assessment of iodine nutritional status of school-aged children, ${ }^{10}{ }^{11}$ this study indicated the difference of UIC between rural and urban school-aged children, suggesting that school-aged children constitute the most important target population that should be paid more attention. We also found the difference of UIC between rural and urban middle-aged people and older people, although they were both falls in optimal iodine status as recommended by $\mathrm{WHO} /$ UNICEF/ICCIDD, suggesting that they could be included in further surveys of iodine nutrition in community if condition will permit, and further studies on the factors induced the difference should be carried out to help to ensure the optimal intake both in rural and urban areas for middle-aged and older people.
Since this paper aims to compare the UIC of rural and urban residents in the Zhejiang Province 16 years after the introduction of salt iodisation by the multiple cluster sampling survey, the differences between rural and urban residents were compared stratified by age group. The investigation was based on the households, and differences of UIC between rural and urban residents were not found among preschool-aged children and adolescent groups limited by their sample size. Young people often eat outside for work reasons; this may reduce the differences between urban and rural areas among these people on diet intake of iodine to a certain extent.

The USI denotes that all edible salt including cooking salt and salt added to manufactured food should be iodised. Traditionally, rural areas have experienced a lower iodine nutritional status due to the economic status and culture of an agrarian lifestyle and lack of health education. However, our study indicated that this is no longer the case, and rural residents have a higher UIC than urban residents, and both of them were in the optimum interval of iodine nutrition interval suggested by the WHO. ${ }^{4}$ Results by multiple logistic regression method indicated that for rural residents, people with young age, living in coastal areas, usually intake pickled products, and intake iodised salt could have higher UIC compared with those without these factors. Urban residents with young age, living in coastal areas, usually intake aquatic products, and intake iodised salt could have higher UIC compared with those without these factors. Results by multiple logistic regression method suggested that table iodised salt intake is the major factor which influences the iodine nutritional status mostly for rural and urban residents, this is consisted with Wu et al's ${ }^{12}$ report under the USI policy. ${ }^{13}$ For rural and urban residents, age is also an influencing factor for UIC, and this result is similar to Pfeiffer et al's ${ }^{14}$ work of NHANES. Salt iodisation assures iodine nutrition in Zhejiang where environmental iodine is widely lacking. In the Zhejiang rural areas, the iodine intake of residents mainly comes from cooking salt for a few manufactured food items in their daily menu. Residents of rural areas may be especially prone to higher salt consumption resulting from eating habits that included more coarse and pickled foods, and this may be one of the causes that induce the difference in iodine levels between rural and urban residents. For rural and urban 
residents, people living in coastal areas had higher UIC than those who were not, and this is consistent with a study carried out in Italy and Sudan; ${ }^{15}{ }^{16}$ for urban residents, those who usually consume aquatic products have higher UIC than those who do not. Aquatic products could help to improve the iodine national status as supplements of iodised salt, although the consumption of aquatic products for iodine intake is low. ${ }^{9} 1718$ Zhejiang Province, located in the southern part of the Yangtze River Delta of the southeast coast of China, lies in the east of the East China Sea, enjoying a vast territory and tropical zones with mountains, hills, plains and coastal terrain. Consequently, it is necessary to consider factors such as rural and urban territories, terrains and living habits when implementing the USI programme and evaluating the iodine nutritional status.

This analysis has several limitations. UICs are highly variable and represent recent intake rather than usual intake. Owing to this variation, a sample of 100 spot urine tests is needed to produce estimates of urinary iodine with a precision range of $\pm 10 \%$, and a sample of 500 is needed for a precision range of $\pm 5 \% .{ }^{19}$ Based on our findings, we find that there are differences between rural and urban residents in iodine levels, but the falls in the optimal iodine status are as recommended by the WHO/UNICEF/ICCIDD. Iodised salt intake is the major factor which influences the iodine nutritional status mostly for rural and urban residents. The ongoing monitoring of population iodine status remains crucially important. Further, monitoring of UIC should differentiate between rural and urban areas.

Contributors GD, XL and YZ were responsible for the study design. YZ was responsible for the data collection and analysis, paper writing and revision. ZM and GM took part in the field investigation and data collection. WZ was in charge of laboratory detection.

Funding This study was supported by the Zhejiang Province science and technology fund (2009C03010-1).

Competing interests None.

Patient consent Obtained.

Ethics approval Zhejiang Provincial Center for Disease Control and Prevention.

Provenance and peer review Not commissioned; externally peer reviewed.

Data sharing statement No additional data are available.

Open Access This is an Open Access article distributed in accordance with the Creative Commons Attribution Non Commercial (CC BY-NC 4.0) license, which permits others to distribute, remix, adapt, build upon this work noncommercially, and license their derivative works on different terms, provided the original work is properly cited and the use is non-commercial. See: http:// creativecommons.org/licenses/by-nc/4.0/

\section{REFERENCES}

1. Andersson M, Karumbunathan V, Zimmermann MB. Global iodine status in 2011 and trends over the past decade 2012;142:744-50.

2. Zhejiang provincial center for disease control and prevention. Endemic diseases. Annals of Zhejiang disease control and prevention. 2000.

3. Zmimmermann MB, Jooste PL, Pandav CS. lodine-deficiency disorders. Lancet 2008;372:1251-62.

4. WHO, UNICEF, ICCIDD. Assessment of iodine deficiency disorders and monitoring their elimination. A guide for programme managers. 3rd edn. Geneva: World Health Organization, 2007.

5. Andersson M, Karumbunathan V, Zimmermann MB. Global iodine status in 2011 and trends over the past decade. J Nutr 2012;142;744-50

6. Wang YL, Zhang ZL, Ge PF, et al. lodine status and thyroid function of pregnant, lactating women and infants (0-1 yr) residing in areas with an effective Universal Salt lodization program. Asia Pac J Clin Nutr 2009;18:34-40.

7. World Health Organization. Vitamin and mineral requirements in human nutrition. Geneva, Switzerland: World Health Organization, 2004:303-17.

8. Chinese Nutrition Society. Chinese dietary reference intakes. Beijing: China Light Industry Press, 2000;193p.

9. Chen JS, Yang WX, Li N, et al. Salt iodization and risk assessment of iodine status in Chinese population. Risk assessment report of salt iodization, 2011.

10. Zou Y, Ding G, Lou X, et al. Factors influencing thyroid volume in Chinese children. Eur J Clin Nutr 2013;67:1138-41.

11. Zou Y, Lou X, Ding G, et al. An assessment of iodine nutritional status and thyroid hormone levels in children aged 8-10 years living in Zhejiang Province, China: a cross-sectional study. Eur J Pediatr 2014. Published Online First: 6 Feb 2014.

12. Wu Y, Li X, Chang S, et al. Variable iodine intake persists in the context of universal salt iodization in China. J Nutr 2012;142:1728-34.

13. Zou S, Wu F, Guo C, et al. lodine nutrition and the prevalence of thyroid disease after salt iodization: a cross-sectional survey in Shanghai, a coastal area in China. PLoS ONE 2012;7:e40718.

14. Pfeiffer CM, Sternberg MR, Caldwell KL, et al. Race-ethnicity is related to biomarkers of iron and iodine status after adjusting for socio demographic and lifestyle variables in NHANES 2003-2006. J Nutr 2013;143:977S-85S

15. Aghini-Lombardi $F$, Vitti $P$, Antonangeli $L$, et al. The size of the community rather than its geographical location better defines the risk of iodine deficiency: results of an extensive survey in Southern Italy. J Endocrinol Invest 2013;36:282-6.

16. Medani AM, Elnour AA, Saeed AM. Endemic goitre in the Sudan despite long-standing programmes for the control of iodine deficiency disorders. Bull World Health Organ 2011;89:121-6.

17. Chen K, Zou Y, Wang JY, et al. [A comparative study on iodine nutritional status of adult islanders in Zhoushan]. Zhonghua Liu Xing Bing Xue Za Zhi 2003;24:370-3.

18. Chen $\mathrm{K}$, Zou Y. lodine nutritional status of adults during a period of salt iodization. J Public Health (Oxf) 2004;26:144-6.

19. Andersen S, Karmisholt J, Pedersen KM, et al. Reliability of studies of iodine intake and recommendations for number of samples in groups and in individuals. Br J Nutr 2008;99:813-18. 